\title{
LA ENSEÑANZA DE LAS PRIMERAS LETRAS EN ESPAÑA EN LA SEGUNDA MITAD DEL SIGLO XVIII: CONTENIDOS Y MÉTODOS A TRAVÉS DE ALGUNOS TRATADOS DE ENSEÑANZA
}

\author{
Sylvie Imparato-Prieur \\ Universidad de Montpellier III
}

\begin{abstract}
RESUMEN. Este estudio considera un conjunto de cuatro tratados de educación publicados en Madrid entre 1780 y 1798. Todos presentan la particularidad de haber sido redactados por maestros, que tuvieron la oportunidad de poner en práctica la enseñanza que preconizaban en varias escuelas de primeras letras de la Capital.

Este artículo analiza los contenidos propuestos y los métodos seguidos, lo que permite definir la enseñanza ideal tal como la concebían los ilustrados en España. Demuestra que estas prácticas pedagógicas corresponden a una concepción nueva del niño y se inscriben en la política reformista de las Luces, en la medida en que no se trata tan sólo de formar al perfecto cristiano: también importa educar al perfecto ciudadano de mañana.

ABSTRACT. This study considers a combination of four education treatises published in Madrid between 1780 and 1798. All of them present the detail of being written by teachers, who could apply the teaching they recommended in different junior school of the capital.

This article analyses the proposed contents and used methods, that permit to define the ideal teaching, as men of Enlightenment in Spain imagined. It demonstrates that these pedagogic methods answer to a child's new conception and are in keeping with the Enlightenment reformist politics, in that it 's not a question to form the perfect christian: it's essential to bring up the tomorrow's perfect citizen.
\end{abstract}

\section{Introducción}

En la segunda mitad del siglo XVIII, el debate se intensifica en España en torno a la educación. Se multiplican los discursos, los planes, las memorias y los tratados, en los que gente muy distinta (religiosos, políticos, pedagogos) presenta su opinión, en general muy negativa, sobre la situación educativa en España, así como sus soluciones para remediar esos males ${ }^{1}$. El tema de la educación apparece emblemático del afán reformista de los ilustrados. Efectivamente, se piensa que con la educación y con la difusión a un amplio público de las primeras letras se logrará una mejora considerable de la situación

1. Sobre este tema, véase mi tesis doctoral, «Education et société dans l'Espagne des Lumières: I'exemple de Madrid (1759-1808)», Universidad de Saint-Etienne, 1995, tomo 1, p. 86-145. 
en particular económica de España. Esto se debe a que principalmente sea la educación de las clases desfavorecidas, a las que hay que poner al trabajo, lo que motive las reflexiones. Para ilustrar esta voluntad de mejora de las primeras letras, la única enseñanza a que tenían acceso los niños pobres, hemos seleccionado cuatro tratados de enseñanza: el Método uniforme para las escuelas de cartilla de deletrear, leer, escribir, aritmética, gramática castellana y ejercicio de doctrina, del Padre Felipe $\mathrm{Scío}^{2}$, publicado en 1780, el Arte de escribir por reglas y sin muestras de Anduaga, publicado anónimamente en 1781 y reeditado bajo su nombre de autor en 1795², las Prevenciones dirigidas a los maestros de primeras letras de Juan Rubio, publicado en $1788^{4}$ y el Arte de escibir por reglas y con muestras de Torío de la Riva, de $1798^{5}$.

Todos estos manuales presentan la particularidad de haber sido escritos por hombres que tuvieron la oportunidad de experimentar su método. Así, el método propuesto por Scío era utilizado en las escuelas pías, el tratado de Anduaga fue experimentado en las escuelas de los Reales sitios de San Ildefonso y Valsaín, con la aprobación de Floridablanca. Rubio finalizó su método en la escuela de San Ildefonso y dio allí tan buenos resultados que el rey impuso en 1791 ese método en las ocho escuelas reales de la Capital. En cuanto a Torío, puso en práctica su teoría en el Seminario de Nobles, y este método fue el que el rey decidió establecer en todas las escuelas de primeras letras del reino en 1801.

Estos cuatro educadores definieron unos contenidos y experimentaron unos métodos y unas técnicas que fueron verdaderamente aplicadas en ciertas escuelas madrileñas, lo que nos permite tener por tanto una idea bastante precisa de lo que se les enseñaba a los niños en la segunda mitad del siglo XVIII. El programa era bastante sencillo: doctrina cristiana (y moral), lectura, escritura, cálculo o aritmética, ortografía y gramática castellanas. Estudiando el aspecto didáctico de estos tratados, este artículo aspira a contribuir al desarrollo de una «historia de la escuela», apuntando a una historia de las evoluciones didácticas en el aula.

\section{Estructura y desarrollo de las Primeras letras}

\subsection{Doctrina cristiana y mora/ ${ }^{6}$}

Según Scío, la principal obligación de los maestros es «infundir el Santo temor de Dios en los ánimos de sus discípulos» ${ }^{7}$. Para alcanzar ese objetivo, propone que el

2. Scío, Felipe, Método uniforme para las escuelas de cartilla, deletrear, leer, escribir, aritmética y exercicio de Doctrina christiana, como se practica por los Padres de las Escuelas Pias, Madrid, Pedro Marín, 1780, 68 p.

3. Anduaga y Garimberti, Joseph de, Arte de escribir por reglas y sin muestras: establecido de orden superior en los Reales Sitios de San Ildefonso y Valsain, después de haberse experimentado en ambos la utilidad de su enseñanza y sus ventajas respecto del método usado hasta ahora en las escuelas de primeras letras, 2a edición con notas, Madrid, Imprenta Real, 1795, 150 p.

4. Rubio, Juan, Prevenciones dirigidas a los maestros de primeras letras, Madrid, Imprenta Real, $1788,42 \mathrm{p}$.

5. Torío de la Riva, Torcuato, Arte de escribir por reglas y con muestras, Madrid, Imprenta de la Viuda de Dn Joaquin Ibarra, 1798, 418 p.

6. Este punto no es desarrollado por Anduaga, lo que aparece lógico, siendo su tratado un Arte de escribir ante todo.

7. Scío, op. cit., p. 1. 
maestro dedique cada mañana y cada tarde un rato a la explicación de la doctrina. Además, será preciso que enseñe a sus alumnos una oración para cada uno de los momentos del día. Por fin, habrá una Academia Pública de Doctrina cristiana para que sea elegido entre los alumnos el «Príncipe» en esa disciplina. Los niños formarán pues un círculo, un alumno empieza haciéndole una pregunta (inspirada en el Catecismo de Ripalda) a un compañero. Si éste sabe contestar, le toca a él hacer otra pregunta a otro alumno. Si se equivoca, el que pregunta tiene que gritar «error», para que el interrogado pueda corregirse, siendo eliminado si no es capaz de hacerlo. Si un alumno hace una pregunta que ya ha sido propuesta, el interrogado debe gritar "ya hecha», lo que excluye al preguntador. El juego sigue así hasta que sólo quede un niño, que se convierte en «príncipe». Esta manera lúdica de tomar las lecciones de doctrina cristiana puede parecer bastante atractiva, pero su principal defecto es que solicita la memoria y no la reflexión. Sólo los niños más atentos y que tienen mejor memoria ganan. Con esto, no se puede saber si han asimilado correctamente los preceptos que se desea inculcarlos.

Este aprendizaje de la religión es casi sistemáticamente vinculado al de la moral y de las costumbres: los alumnos tienen que estudiar una buena máxima relativa a las costumbres, seleccionada por el maestro en el libro de un buen autor profano. Para concluir, Scío añade una formación cívica, cuyo objetivo es hacer de los niños unos buenos ciudadanos, y que consiste en enseñarles la obediencia y el respeto de Dios y de la religión, del Rey, de la justicia, de los padres y de sus conciudadanos. El maestro debe hacer que aborrezcan la ociosidad y advertirlos de los peligros que les amenazan, de no ganarse la vida honradamente.

Pero Scío no sólo define un programa religioso y moral para las horas de clase, también precisa cuanto debe hacer el niño desde el momento en que se levanta hasta que se acueste y expone una serie de reglas que el maestro deberá leerles a los alumnos el sábado, para que éstos aprendan a ejercerlas: levantarse temprano, santiguarse, vestirse pensando en cosas "santas y útiles» ${ }^{8}$, rezar de rodillas, ya vestido, hacer sus tareas de clase, peinarse, lavarse la cara y las manos, desayunar limpiamente, cuidando de sus maneras, besarles la mano a sus padres antes de irse a la escuela. Scío determina luego la actitud que debe adoptar el niño en la escuela: atención, docilidad, claridad en la manera de expresarse, rapidez en la ejecución de las tareas: tales son las cualidades de que deberá gozar el perfecto alumno. Scío pormenoriza así cada uno de los momentos de la vida del niño, porque quiere convertirlo en un ser ideal, enteramente dedicado a la oración y al estudio. El niño tiene que hacer la síntesis de todas las virtudes y de todos los talentos. Este deseo de encauzar al niño, reglamentando cada uno de los instantes de su vida, precisando incluso cuáles han de ser sus juegos, traduce de hecho una profunda inquietud. Los niños de las escuelas pías son pobres y sus padres no parecen ser capaces, a juicio de Scío, de educarlos cristiana y moralmente. El maestro debe por tanto sustituirse a estos padres para el bienestar de la sociedad, pues no cabe duda de que esos seres bien educados a los que se quiere fabricar son de hecho la población ideal que la Iglesia y la sociedad necesitan. Es

8. Ibid, p. 2. 
necesario que los niños no reproduzcan los errores de los padres, de allí esa enseñanza global en el marco escolar.

Rubio se preocupa ante todo de la manera en que el maestro va a transmitir sus conocimientos religiosos. También recomienda el recurso a la memoria, tanto para los que no saben leer como para los que ya lo saben. Este estudio debe hacerse partiendo de un catecismo, y debe también acudir a un catecismo histórico. No cabe duda de que se refiere implícitamente a los catecismos de Ripalda y Fleury. El maestro deberá enseñarles a los niños a decir "con fervor» sus actas de fe y de contrición. Sigue una lección de moral, en la que predomina el valor del ejemplo. Efectivamente, es gracias al ejemplo, es decir mostrando él mismo una gran suavidad, como logrará el maestro inculcarles a los alumnos estas maneras y buenas costumbres de cristiano. En cuanto al contenido moral, es de notar que encontramos en él las mismas preocupaciones y exigencias que en Scío: quiere alejarlos de la ociosidad, mostrándoles las ventajas del buen oficio. Incluso define lo que es un buen trabajo para esos niños: labrador, artesano u obrero, tales son las funciones a las que pueden pretender los niños de esas escuelas. Cabe precisar que el público al que se dirige Rubio es humilde, tal como lo era el de Scío, se trata de los hijos de las clases desfavorecidas que deben dedicarse al trabajo. Rubio no disimula sus intenciones, ya que aconseja «procure el maestro que aprendan pronto y útilmente sus Discípulos, para que no eternizándose en la Escuela, ni endureciéndose en ella para el trabajo, puedan emprenderlo en unas edades oportunas. De aquí resultará el honor del Maestro, el bien del Estado y el mejor servicio de Dios» ${ }^{9}$. Se trata de preparar a estos alumnos a su vida de trabajo futura y es la única finalidad de las clases de doctrina cristiana y de moral que se les da. Informándoles de sus obligaciones morales, civiles y cristianas, los maestros indican a los niños la vía que tienen que seguir para hallarse completamente integrados en la sociedad.

Torío de la Riva adopta el mismo parecer que Scío y Rubio ${ }^{10}$. Cita a Ripalda y Fleury, y basa él también su método de aprendizaje en la memoria. Pero, y en esto aparece la diferencia más notable, Torío considera que este saber será superficial si no viene fortalecido por las lecciones y los ejemplos que dará el maestro, teniendo en cuenta la edad de sus alumnos para que estos ejemplos sean fácilmente comprensibles.

Su capítulo sobre la urbanidad une, como en los otros autores, la práctica religiosa y la moral. Torío precisa lo que deben hacer los niños (oraciones, misa, confesión, por ejemplo), pero añade que el maestro debe también enseñarles el respeto, así como la manera de comportarse con sus semejantes, sean inferiores, iguales o superiores socialmente. Este deseo de hacer que el niño pueda comunicar con soltura con cualquier conciudadano muestra que el autor desea formar al hombre, y no sólo al trabajador respetuoso y disciplinado. Considera que sus alumnos pueden tratar con inferiores, lo que indica que el público no es exactamente el mismo que en los tratados anteriores. En realidad, cabe recordar que Torío redactó su método pensando primero en su propio público, el del Seminario de nobles. Era lógico que Torío pensara

9. Rubio, Juan, op. cit., p. 37.

10. Torío de la Riva escribe un Arte de escribir que sobrepasa los límites de esa materia, ya que propone, al contrario de Anduaga, un método global de educación así como un pequeño tratado de civilidad. 
en hacer de sus alumnos unos hombres relajados en sus relaciones con los demás, cuando Scío y Rubio ni siquiera se planteaban la pregunta, ya que bastaba con que sus alumnos fueran respetuosos y obedientes, es decir con que aceptaran su inferioridad. Más tarde, se democratizó el método de Torío en cierta medida, cuando se decidió extenderlo a las escuelas de todo el reino.

Hace hincapié Torío en otro aspecto: la necesidad de cuidar de la limpieza y aseo de los niños, de sus buenos modales al comer, en la calle, en las pláticas y en los juegos. Sigue con la idea de formar a individuos que puedan sentirse a gusto en cualquier circunstancia de la vida cotidiana, que sabrán comportarse debidamente. En Scío encontramos una referencia a la limpieza y al decoro, pero se trata para él de una manera de evitar que los niños caigan en el vicio. Precisa cómo deben comportarse los niños en su vida íntima, no dice cómo tienen que actuar cuando se hallan con otras personas. Rubio ni siquiera enfoca ese asunto.

En lo que se refiere a la doctrina cristiana y la moral, religiosos y seglares parecen compartir los mismos pareceres. Todos intentan formar el alma de sus alumnos, porque todos afirman servir a la vez los intereses de Dios y del Rey, es decir en realidad los de la Iglesia y del Estado que todos sirven más o menos directamente. Las diferencias que se pueden notar entre ellos se deben a la calidad del público de referencia y a los propósitos apuntados, y no al estado (seglar o religioso) del educador. Si las divergencias son mínimas en cuanto a doctrina y moral, parece que tal no sea el caso para la lectura.

\subsection{Lectura}

Los cuatro maestros recomiendan que se divida la clase en tres secciones, que por supuesto no llevan el mismo nombre aunque tengan aproximadamente las mismas actividades.

Para Scío, el primer nivel es el de la escuela de cartilla, que se divide a su vez en diez clases. Las cuatro primeras trabajan cada una en un tablero en el que está reproducida la cuarta parte del alfabeto. Los alumnos deben leer las letras de su tablero en cualquier orden. Cuando los alumnos conocen un tablero, pasan a otro. Cuando se saben los cuatro, pasan a la quinta clase, donde trabajan el conjunto de los tableros. Se aplica luego el mismo sistema para las sílabas (tres clases, más una para los que conocen las tres anteriores). La décima y última clase trabaja en un tablero que lleva palabras y frases, y cada alumno debe leer o una palabra o una frase. Cada sábado por la mañana, el maestro aprecia los progresos de la semana, y atribuye premios. Para acceder a la clase superior, los niños han de examinarse ante el Padre Prefecto o el padre Rector.

Los alumnos pasan así a la escuela de deletrear, en la que se recomienda el deletreo silábico y consecutivo, en vez del tradicional deletreo. Los alumnos vienen repartidos en seis clases. La primera trabaja en un tablero donde aparecen frases en letra cursiva. La segunda estudia la puntuación en un libro. La tercera estudia el prólogo del libro previsto para esta enseñanza, y a propósito del cual no tenemos ninguna información. Todos los niños deben poseer la misma edición de dicho libro, donde las palabras vienen divididas en sílabas. La cuarta sección lee la primera parte del libro, 
en la que las palabras ya no están divididas. La siguiente clase trabaja en la segunda parte del libro, impresa en letra cursiva. Conviene que cada clase tenga unos veinte $o$ treinta alumnos. Cada alumno tiene a un «rival»: uno empieza a deletrear, el otro sigue para corregirle. El maestro puede intervenir en cualquier momento, y los papeles se intercambian. Scío parece muy satisfecho de ese sistema, pues según él, los niños temen ser soprendidos y esto les incita a seguir con atención. La sexta clase es para los que saben leer con soltura todas las sílabas.

Cuando los niños han aprobado el examen, acceden a la tercera escuela: la escuela de leer, que se divide en siete clases. La primera acoge a los alumnos que acaban de llegar de la escuela anterior y que trabajan en unos tableros donde aparecen escritos las cifras árabes, romanas, las abreviaciones, etc. Las seis otras clases trabajan en una de las seis partes del libro previsto para esta escuela. Este libro, que ha de ser el mismo para todos los niños, es en realidad una compilación, en la que tenemos la primera parte del Catecismo de Fleury, extractos de De los nombres de Cristo de Fray Luis de León, cartas de Santa Teresa, la Introducción a la sabiduría de Vives y reglas de ortografía. Cada parte de este libro tiene una tipografía diferente (grandes caracteres, letras «en enredos» y letra cursiva). Después de este trabajo intensivo, cuando el niño termina este recorrido, sabe leer y puede pasar a la escuela de escritura.

Scío fragmenta cada una de las secuencias de aprendizaje de la lectura, por que su método está previsto para clases numerosas. Eso explica que haya establecido una especie de pedagogia interactiva en la que los alumnos se vigilan y se corrigen unos a otros, método sin el cual el maestro no podría enseñar nada. Este desempeñaba pues el papel de supervisor, teniendo la obligación los niños de trabajar solos. Para reforzar el control, Scío instituye para cada grupo de veinte alumnos un «Gobernador», alumno meritorio, que hace repetir las lecciones a los alumnos.

El método utilizado por las escuelas pías era muy apreciado, lo que parece indicar que era superior a los que se solía utilizar y que sólo se basaban en el deletreo. Cabe notar que ese método era muy progresivo, los alumnos podían sin duda seguir su propio ritmo de aprendizaje, como lo da a pensar la práctica de los controles semanales.

Anduaga es mucho más rápido a la hora de presentar su propio sistema. Empieza criticando el método utilizado por la mayoría de los maestros de España, para luego hacer su propia sugerencia, diciendo que se parece al método que utilizan los escolapios en 1780 (y que acabamos de pormenorizar). Divide como Scío a los alumnos en tres clases: la tercera es constituida por los que aprenden las letras y el principio del deletreo, la segunda deletrea y la última lee con fluidez y perfeccionan la prosodia. Anduaga no precisa si adopta el deletreo silábico recomendado por Scío o si sigue el deletreo clásico. Podemos pensar que sigue con el método clásico.

Para cada clase, se elige a un Celador entre los alumnos más meritorios de la clase superior. Anduaga presenta luego su método, basándose en una cifra de doce alumnos por clase. El celador lee la lección dos veces en voz alta. Luego, cada uno la estudia solo cuatro veces, haciéndole al celador todas las preguntas necesarias. Cuando todos han terminado, el celador interroga a un alumno, mientras los demás siguen. Los alumnos ven así otras dos veces la lección. Con este método, la lección es vista diez veces por la mañana, y es repetida otras diez veces por la tarde. Se trata de puro machaqueo, y se puede decir que los niños en realidad se saben la lección de memoria. Nada mues- 
tra ni permite verificar que la lección ha sido comprendida, aunque esto parece ser secundario en un sistema educativo que de todas formas privilegia la memoria. Así, Anduaga está muy satisfecho de su método ya que le permite al maestro estar siempre enterado de los adelantos de los alumnos, que además integran nociones de orden y método. No cabe duda de que los niños acaban memorizando el conjunto de los sonidos, y que por consiguiente son capaces de leer al final de su aprendizaje. El principal interés del método de Anduaga es que aconseja que se les enseñe a escribir a los niños en cuanto conozcan las letras, lo que aparece como una notable novedad. Las dos enseñanzas son llevadas paralelamente, lo que evita la fragmentación de los saberes. Encontramos algo parecido, aunque menos audaz en Rubio, que incluye en las clase superior de lectura a los que están aprendiendo a escribir.

En cuanto a la lectura, Rubio recomienda un método que nos parece algo diferente de los que vimos antes. Reparte igualmente la clase de leer en tres subgrupos: los que se ejercitan en el aprendizaje de las letras, los que leen las sílabas y por fin los que recitan de memoria ( $l$ los que decoren»). La primera diferencia es que reprueba el uso de las cartillas y que condena el deletreo: «el que los niños hagan las combinaciones en un silabario bien ordenado, sin usar del impertinente y vulgar deletreo, es cosa provechosa y breve» ${ }^{11}$.

También Rubio aconseja la repetición y el uso de la memoria, pero inicia el aprendizaje de la memoria de una manera más lúdica: propone el empleo de cartones móviles, con sólo una letra. Les da a los alumnos hojas que llevan también una letra, y les incita a comparar las letras que tienen con las que aparecen en los cartones móviles y a nombrarlas. Supone cierta gimnasia intelectual, que no se daba en los métodos precedentes. Se puede pensar además que era más fácil para los niños recordar letras que ellos mismos habían descubierto.

En cuanto a la clase superior de lectura, donde también aprenden a escribir, Rubio propone que cada mañana o tarde sea dividida en dos secuencias y los alumnos en dos grupos. Un grupo lee mientras el otro escribe, y luego se invierten las actividades. Rubio recomienda que los maestros no cambien de actividad de manera arbitraria, sino que vayan sustituyendo a los niños que hayan acabado de escribir por niños de la clase de lectura. Esa voluntad de adaptarse a las diferencias de niveles expresa un real deseo de que los niños asimilen unos conocimientos equivalentes, teniendo en cuenta las diferencias de aptitudes intelectuales y sin apresurar a los niños. Esa manera de actuar es tan poco frecuente en los tratados de la época que merece ser subrayada.

Para que el sistema funcione de manera eficaz, Rubio propone la elección de seis celadores (dos para cada una de las tres clases) procedentes de la última clase que cuidarán de la tranquilidad en el aula, de que los niños digan sus lecciones y que transmititrán al maestro todo lo que juzguen necesario. El sistema es muy codificado: el maestro empieza la jornada tomándoles la lección de lectura a los celadores. Luego, uno de los dos celadores de cada clase se pone a escribir sus páginas de escritura. Mientras tanto, los tres celadores que quedan se hacen cargo de su respectiva clase. Los

11. Rubio, op. cit., p. 29. 
papeles se invierten luego. En esa repartición, se preven también clases de aritmética y de ortografía, dadas por el maestro y que tienen que presenciar los seis celadores.

Rubio preconiza, tal como Anduaga, de quien se inspira, y Scío, una enseñanza que prefigura la que se desarrollará en el siglo XIX bajo el nombre de «enseñanza mutua». En efecto, los celadores, alumnos ellos también, sirven para motivar y arrastrar en cierta medida a los niños de que cuidan. Se establece un sistema de intercambio, que por cierto no es una completa novedad, ya que recuerda el sistema de las decurias que los jesuitas habían instaurado en sus colegios ${ }^{12}$.

Torío de la Riva sigue un sistema bastante parecido: divide a sus alumnos en cuatro clases, tres de las cuales viene reservadas al aprendizaje de la lectura. La última (clase superior) reúne a los que aprenden a escribir y a contar. Si se considera el contenido de la enseñanza de las tras clases de lectura, no aparecen diferencias con la repartición seguida por los otros educadores. La primera clase es la de los niños que sólo aprenden a reconocer las letras. La segunda reúne a «los que silabean o deletre$a n{ }^{13}$. La tercera es para los que leen con fluidez. Es de notar la vacilación de Torío en cuanto a la técnica de aprendizaje de la lectura: no parece haber elegido entre la lectura de las sílabas y la de las letras, como si dejara la libertad a cada maestro de elegir el método que le pareciese más conveniente. Muestra esto que a finales del siglo XVIII, la elección entre el deletreo y el silabeo aún no se había hecho. Cabe añadir sin embargo que el tratado de Torío se dedica más particularmente a la escritura, y en eso es en donde quiere imponer su método. Quizás esto pueda explicar la libertad que les concede Torío a sus colegas.

Para terminar este capítulo sobre la lectura habría que aludir a otro tratado publicado seguramente a principios del siglo XIX y redactado por Vicente Naharro, de quien se sabe que había sido nombrado maestro en Madrid en 1780 y que era miembro del Colegio Académico de Primeras Letras de la capital. En ese tratado titulado Recopilación de los varios métodos inventados para facilitar la enseñnaza de leer ${ }^{14}$, Naharro sintetiza todos los métodos que existen enjuiciándolos. Considera las técnicas francesas, métodos basados en juegos de naipes, tableros, etc. para citar a continuación el método seguido en España, el deletreo, condenándolo. Cita en particular a Palomares y a Torío de la Riva, que la utilizan ambos, los que nos revela indirectamente lo que había seleccionado Torío en su escuela. Pero el verdadero interés del tratado de Naharro, más allá del aspecto anecdótico, es que nos muestra que existía en la época en España una verdadera reflexión acerca de la pedagogía de la lectura. La actitud de Naharro es interesante en la medida en que hace la síntesis de cuanto existe para luego proponer un nuevo enfoque. Pondera cada método y acaba acercándose a los más «progresistas» de los educadores, aconsejando el «método orgáni-

12. Sobre este punto, véase los artículos de J. Ruíz Berrio, «Reformas de la enseñanza primaria en España: la reforma escolar desde las aulas» in L'enseignement primaire en Espagne et en Amérique latine du XVIIlème siècle à nos jours, Tours, publications de I'Université de Tours, 1986, p. 13-14, y de J. R. Aymes, "Les ilustrados espagnols de la seconde moitié du XVIIlème siècle et l'enseignement élémentaire», in Ecole et société en Espagne et en Amérique latine, Tours, CIREMIA, 1983, p.35.

13. Torío de la Riva, op. cit., p. 160.

14. Naharro, Vicente, Recopilación de los varios métodos inventados para facilitar la enseñanza de leer, Madrid, [?], [1800?], 176 p. 
co», que se basa en las sílabas y sobre todo en el aprendizaje de los sonidos del idioma, con un léxico claramente fonético ${ }^{15}$. Esto expresa un enfoque más científico del aprendizaje de la lectura, e indica que el deletreo va perdiendo su supremacia en beneficio de métodos más «modernos» que prefiguran lo que será la enseñanza de la lectura posteriormente. Sin embargo, la posición de algunos educadores más innovadores no debe hacernos olvidar que muy seguramente, la mayoría de los maestros de Madrid y del resto de España debían de utilizar el deletreo, a pesar de los defectos que se le achacaban. Rubio aparece en ese sentido como un precursor, pero se puede dudar de la eficacia de la obligación que se les hizo a los maestros de las Escuelas Reales de utilizar este método en 1791, cuando se sabe que estos maestros ya gestionaban una escuela en Madrid y que esas creaciones son de hecho transformaciones. Conociendo la inercia y la falta de exigencias intelectuales que caracterizaban a los maestros del Colegio Académico, se puede dudar de la capacidad de adaptación de los maestros al nuevo método.

El arcaísmo y la rutina no son privativos de la lectura. La escritura presenta los mismos conflictos entre partidarios del método clásico y adeptos de una nueva técnica, entre seguidores de las muestras y defensores de las reglas.

\subsection{Escritura}

El método que se solía utilizar en España en aquella época se basaba en la imitación de modelos de escritura. El niño tenía que reproducir las mismas letras, incesantemente, hasta lograr que se parezcan al modelo dado por el maestro y dominar así la escritura. Como lo subraya P. Demerson, «para la mayoría de los chicos, la clase de escribir es un escollo difícil de salvar, y permanecen en ella largo tiempo» ${ }^{16}$.

En 1776, Palomares publica un Arte nueva de escribir, ${ }^{17}$ en que la única novedad consiste en ofrecer nuevas láminas donde se reproducen muestras de letras y cortas frases. Esta publicación indica que el método de las muestras era aún utilizada por muchos maestros. Scío, por ejemplo, lo recomienda para las escuelas pías, aunque completándolo con el uso de los palotes, esa líneas paralelas e inclinadas que guiaban la mano del niño. El objetivo es enseñar a los niños una forma única de letra, «un medio entre la bastarda y la redondilla» ${ }^{18}$, destinada a convertirse en el modelo nacional. La puesta en práctica de un modelo nacional indica que el individuo no tiene la posibilidad de «crear»su propia forma de escribir. No basta con que su escritura sea clara y leíble, aún tiene que conformarse con los cánones impuestos por las muestras. El niño no goza de ninguna libertad, y esto es aún más evidente cuando se considera

15. Naharro utiliza los términos: «labiales», «linguales dentales», «linguales palatinos» y «guturales», op. cit., p. 162-163.

16. Demerson, Paulette, «Tres instrumentos pedagógicos del siglo XVIII: la Cartilla, el Arte de escribir y el Catón» in L'enseignement primaire en Espagne et en Amérique latine du XVIIlème siècle à nos jours, Tours, Publications de I'Université de Tours, 1986, p. 32.

17. Palomares, Francisco Javier de Santiago, Arte nueva de escribir inventada por el insigne maestro Pedro Diaz Morante, e ilustrada con muestras nuevas, y varios discursos conducentes al verdadero Magisterio de primeras Letras, Madrid, Sancha, 1776, 136 p.

18. Scío, op. cit., p. 22. 
la cantidad de detalles en la manera de situar el cuerpo y la mano: nada es olvidado, y se entiende mejor que muchos niños hayan tenido dificultades para dominar perfectamente un ejercicio tan delicado.

Como en las diferentes clases de lectura, Scío calcula cada uno de los momentos de la jornada de los alumnos. Durante la primera media hora de clase, repasan las lecciones de doctrina cristiana y preparan su papel y su pluma. Luego, cortan su pluma y dan las lecciones. Durante una hora y quince minutos, se ejercitan en la escritura. El maestro corrige esas páginas durante quince minutos. La última media hora de clase se dedica a la repetición de un capítulo del catecismo de Ripalda o del de Fleury. Para ello, los niños se ponen de pie en los pupitres, y por grupos de unos doce niños, se toman las lecciones unos a otros. Quizás pueda verse en ese ejercicio una manera de agilizar un poco a unos niños crispados durante más de una hora en su folio. El mismo programa se aplica por las tardes, con una leve variación ya que durante la escritura de la última plana, uno de los niños les hace salmodiar la tabla de multiplicar a sus compañeros.

Ese método de aprendizaje de la escritura no satisface a ciertos educadores que se dan cuenta de que muchos niños tienen enormes dificultades y salen de la escuela con una escritura malísima. Así, en 1781, Anduaga aconseja en su Arte que se les enseñe a los niños a escribir a los siete años, es decir en el principio de su escolaridad elemental, porque considera que a esa edad, todos los niños tienen la fuerza suficiente para escribir, y que no es necesario pues dilatar este aprendizaje. Por lo tanto, no prevé una clase particular para la escritura, los alumnos de la segunda clase de lectura (la de "deletreo») se pondrán en paralelo a escribir. Anduaga tiene una concepción más global de las primeras letras, y esta idea es recuperada en cierta medida por Rubio, que prefiere dedicar la clase superior de lectura a esta enseñanza, como vimos anteriormente.

En cuanto al método por sí mismo, Anduaga insiste tanto como Scío en la posición de las manos y del cuerpo, pero les recomienda a los maestros que enseñen a escribir a los alumnos a partir de reglas y no de muestras. Asimiladas esas reglas por el niño, éste podrá escribir con soltura y rapidez. La principal ventaja de su método, como lo apunta Anduaga, es que los niños podrán aprender todo tipo de caracteres, y no un carácter único, como es el caso para las muestras. Lo que le aparecía una ventaja a Scío es visto como una tara por Anduaga, que prefigura lo que se convertirá en una constante en la enseñanza ulterior de las primeras letras: la escritura es vista como una interpretación individual de una serie de normas. Ampliando el número de normas de escritura, Anduaga les ofrece a los niños la posibilidad de adoptar la que manejan con más facilidad. Eso hace más ameno el aprendizaje de la escritura, puesto que ya no hay una sino varias formas de escribir, y todas son correctas. El reproche que se le podría hacer a Anduaga es que sus reglas son tan complejas que los niños no pueden comprenderlas solos: el maestro debe asimilarlas para luego transmitirlas a los alumnos. Ese trámite suplementario, respecto al método de las muestras que no necesita ningún esfuerzo intelectual para el maestro, puede explicar que el método de Anduaga haya sido ampliamente criticado. Sin embargo, tuvo un real éxito, incluso fue reeditado con nombre de autor esta vez en 1795. Además, su método fue recomendado y utilizado por Rubio en las escuelas de su responsabilidad. A partir de 1791, fue impuesto como método único para las Escuelas Reales, después de que Rubio hubiera introducido algunas modificaciones. No se le había escapado la complejidad de las reglas de 
Anduaga, por eso Rubio aconseja a los maestros que utilicen en paralelo «una colección de buenas muestras ${ }^{19}$, que podrán ser analizadas y comentadas con los alumnos. Ya no se trata de una mera imitación en la medida en que el maestro puede incitar a sus alumnos a que reflexionen sobre tal o cual forma de escritura.

Para llevar a cabo esta enseñanza, Rubio propugna una división en tres clases: los principiantes, que aprenden las reglas, ilustrándolas en el tablero o en el folio, «los que escriben con caídos, o sin ellos en los tamaños gruesos» y «los que lo hagan en los medianos y regular» ${ }^{20}$.

Parece que el método de Anduaga haya sido bastante bien acogido en los años de 1781-1795, pero en 1798, Torío de la Riva publica su Arte de escribir donde critica violentamente el método de Anduaga, como lo subraya J. Ruíz Berrio, que percibe esta crítica como una mala interpretación por Torío de las finalidades de Anduaga: «Acusa Torío a Anduaga de haber copiado su método del que en 1614 publicó el P. Pedro Flórez, de la Compañía de Jesús en Madrid, y, por otra parte, tachó de monstruosos y ridículos los caracteres de Anduaga. En fin que, como otras personas, se fijó solamente en la caligrafía, cuando no era ésa la intención de Anduaga. [...] El método de Anduaga es algo mucho más amplio que la cuestión de la caligrafía. [...] su fin era demostrar la necesidad que había de reglas, de método, para la enzeñanza primaria. ${ }^{21}$.

Anduaga puede ser visto como un precursor, y a pesar de los reproches que se les puede hacer, tiene el mérito de haber intentado poner un poco de coherencia en un sistema que carecía de ello por completo. Fue este mensaje el que percibió el Estado, que lo mandó aplicar en ciertas escuelas. Pero no cabe duda de que ciertos maestros no podían aceptar que un método les fuera impuesto, tanto más cuanto que debía de ser muy lucrativo difundir su propio método. Así, creo que las críticas de Torío eran bastante interesadas y más bien justificadas por un deseo de ver adoptado su método a expensas del de Anduaga, lo que se logrará en 1801, fecha en que se impone el Arte de Torío en las escuelas del Reino. Este aspecto lucrativo no pone en tela de juicio la validez del método de Torío, que efectivamente parece más adaptada a las necesidades de los niños. Pero su método no es nada innovador, ya que Rubio, sin redactar un Arte de escribir, recomendaba la utilización de muestras para facilitar el aprendizaje de la escritura. Torío recupera pues las buenas ideas de sus antecesores, añadiendo un pequeño toque personal, y sobre todo incluyendo en su libro lecciones de aritmética, de urbanidad, etc. Finaliza un manual completo de la enseñanza de primeras letras, y éste es el principal interés del tratado.

Torío expone a su vez una repartición del tiempo escolar (una jornada de seis horas ${ }^{22}$, con una separación entre los que aprenden a leer y los que aprenden a escribir. De un punto de vista didáctico, Torío aconseja que se haga una misma lección a todos los alumnos de una clase, sin volverse hacia atrás ni dar explicaciones particulares, excepto si sobra tiempo. Según él, todos los niños tienen derecho al mismo

19. Rubio, op. cit., p. 30.

20. Rubio, ibid, p. 9.

21. Ruíz Berrio, Julio, "Reformas de la enseñanza primaria en la España del despotismo ilustrado: la reforma desde las aulas» in L'enseignement primaire..., op. cit., p. 13.

22. Torío de la Riva, op. cit. p. 161. 
trato, sin diferencias ni privilegios. Este deseo de Torío es interesante en la medida en que refleja una concepción muy peculiar y muy «actual» de lo que ha de ser la «enseñanza pública», según la expresión que él mismo utiliza. La uniformidad no debe hacerse tan sólo a nivel del contenido de las enseñanzas o de los métodos de aprendizaje de las diferentes disciplinas, también es necesario que todos los alumnos reciban la misma atención y las mismas explicaciones de parte del maestro. Este no debe reparar en los casos particulares, sino imponer un ritmo a todos. Por supuesto, podrá ayudar a los alumnos con dificultades siempre que no penalice esto a los demás alumnos. Esto evoca ya la noción moderna de programa escolar, ya que se puede considerar que Torío establece un programa para cada clase que debe ser seguido por todos. Si los alumnos no pueden seguir, no podrán acceder a la clase superior. Este deseo de que los niños sigan un mismo ritmo aparece como una especificidad de Torío, pues en los otros educadores, el sistema era más flexible.

La escritura, mucho más que la lectura, se presenta como la base de una verdadera lucha entre tres grandes tendencias: los que propugnan el uso exclusivo de las muestras, los que se oponen a su utilización y creen sólo en las reglas, y por fin los que privilegian una vía media, con la unión de las reglas y de las muestras, de la teoría y de la práctica. El Estado se interesa en el debate, se aleja de la primera posición juzgada demasiado retrógrada, y adopta sucesivamente con un intervalo de diez años los dos otros métodos. El pragmatismo parece imponerse, pues el Estado sólo adopta los métodos que han sido probados y que han dado resultados. Muestra esto que el Estado confía en los maestros para encontrar nuevos métodos y que viene exigiendo de ellos una verdadera reflexión intelectual y pedagógica, en busca de una mejor eficacia de la enseñanza.

Se nota el mismo deseo de eficacia en la enseñanza de la aritmética, que los educadores van a intentar racionalizar y simplificar, además de imponerla, pues, muchas veces, los niños salían de la escuela sin haber adquirido las bases de esta disciplina.

\subsection{Aritmética}

El sentido que cobra esta palabra en el siglo XVIII es más reducido que hoy en día, pues entonces se trataba tan sólo de las cuatro operaciones. Esta materia parece presentar tan poco interés hasta entonces que nadie había propuesto un manual para enseñar la aritmética. En 1801, con el libro de Torío, se impone un método de aprendizaje de la aritmética, que prevalece sobre los que se usaban anteriormente.

Scío limita a las cuatro operaciones el conocimiento de la aritmética, siendo los niños pobres los que acudían a las escuelas pías, lo cual le parece hacer innecesario cualquier profundización del tema. Reúne en la quinta y última clase a los que saben ya escribir correctamente, y la subdivide en diferentes secciones que corresponden a las diversas operaciones (clase de numerar, sumar, restar, etc.), con el objetivo de facilitar el aprendizaje. Se da aquí de nuevo la fragmentación de los saberes tan característica de Scío. El método que utiliza para enseñar una operación es bastante sencillo: en un encerado, el maestro escribe una operación, la soluciona explicándola a los alumnos. Luego la borra y escribe una nueva operación, pero les toca a los alumnos resolverla paso a paso. Al final de la demostración, borra el resultado, y les pide a los alumnos que copien 
las cifras y que resuelvan la operación para el día siguiente ${ }^{23}$. Este método es algo expeditivo, pues parece poco probable que los alumnos hayan comprendido al cabo de dos explicaciones cómo funciona la operación. Además el ejercicio propuesto recurre más a la memoria que a la verdadera explicación de los fenómenos de cálculo. El método de Scío ofrece sin embargo la ventaja de hacer participar a los alumnos en la resolución de la operación, la explicación no es tan sólo magistral.

Rubio comparte la opinión de Scío en cuanto al método apropiado para enseñar el cálculo: afirma que «las cuentas deben enseñarse demostrativamente. Hacen muy mal los Maestros en dejar ignorar a los Discípulos las razones en que se funda cada operación ${ }^{24}$. Con ese método, y con una hora de lección diaria durante un mes, cualquier alumno medianamente dotado será capaz de resolver las cuatro operaciones. Cree en las virtudes de la explicación, pero no da ningún título de libro, no define ninguna técnica precisa. Se sabe sin embargo, por una Orden Real del 24 de noviembre de 1796 que la Aritmética publicada por Lucas María Romero era utilizada en las escuelas colocadas bajo la dirección de Rubio ${ }^{25}$, que parece estudiar lo que se suele hacer y seleccionar lo que juzga más conveniente para el tipo de enseñanza que quiere difundir.

Torío de la Riva tiene más ambición. Como hemos visto, él quería crear un curso completo de primeras letras. En cuanto a la aritmética, tan sólo detalla y explica a los maestros lo que deben enseñar a sus alumnos: las cuatro operaciones de los números enteros, de las fracciones y de los números complejos. Estos dos últimos puntos supone una profundización respecto a lo que proponía Scío por ejemplo. Explica a continuación en que consiste cada una de esa operaciones y propone una serie de preguntas y respuestas para que el maestro pueda verificar los conocimientos de los alumnos, lo que evidencia un fuerte apoyo en la memoria como método de enseñanza. No da más indicaciones en cuanto a la manera concreta de enseñar tal o cual operación, como si los maestros lo supieran de sobra. Debía de estimar que una vez fijados los contenidos, les sería fácil a los maestros adaptar y transmitir este saber.

Doctrina, lectura, escritura y aritmética constituyen el fundamento de las primeras letras, pero nuestros educadores añaden otras dos disciplinas, que no se solían enseñar en las escuelas de la época y que ellos querían imponer.

\subsection{Ortografía y gramática castellanas}

Consideramos estas dos disciplinas de manera conjunta porque a menudo eran estudiadas juntas. Como para la aritmética, sólo se puede analizar a Scío, Rubio y Torío, ya que Anduaga no alude al tema.

Muy lógicamente, Scío incluye el aprendizaje de la ortografía en la clase de escritura. El conocimiento de la ortografía que preconiza consiste en dar las bases para que los niños sepan escribir correctamente. Estudia pues todas las letras del alfabeto, dice en qué cirscunstancias se usan, precisa el empleo de las mayúsculas y de los signos de puntuación. La gramática le parece algo más complejo, por tanto piensa dedicarle

23. Scío, op. cit., p. 42.

24. Rubio, op. cit., p. 31.

25. Archivo Histórico Nacional, Estado, Leg. 3215, exp. 219. 
un año entero, después del estudio de la aritmética. El maestro dará por la mañana una clase de historia de la lengua castellana y una clase de Gramática de la Real Academia. Por la tarde, los alumnos escucharán una clase de Historia de España y otra clase de gramática. Las lecciones serán explicadas por el maestro, y el alumno tendrá que ser capaz de decirlas. Pero no basta con que el niño las sepa de memoria, también tiene que saber aplicar las reglas en unos ejercicios. Para eso, Scío prevé unas sesiones de exámenes los sábados. Para terminar este año de práctica, se celebrará «una academia pública», en la que los alumnos podrán decir una declamación preparada para esta ocasión. Luego se les interrogará sobre la historia de España, lengua castellana y gramática, explicando las reglas con la ayuda de buenos autores.

Esta enseñanza de la gramática y el principio de las oposiciones públicas vienen inspirados por las clases de latinidad, que podrán cursar ulteriormente los niños que hayan demostrado reales dotes escolares. Incluso prevé Scío una iniciación al latín para los que quieran pasar a la clase de latinidad. Por cierto, podría ser esto la prueba de que la clase de gramática castellana estaba abierta a todos, y que sólo los que querían o podían se preparaban al latín. Pero, el hecho de que un año suplementario después de la clase de aritmética fuera dedicado a este estudio da que pensar que muchos niños debían de abandonar entonces sus estudios y que pues la clase de gramática venía reservada a unos pocos y que era una preparación a la latinidad antes que el final de la enseñanza primaria.

Rubio tiene un punto de vista menos elitista sobre el tema, puesto que no distingue la ortografía de la gramática. Sólo quiere transmitir a los alumnos «las reglas generales de la Ortografía castellana, y las nociones de la Gramática de nuestra lengua ${ }^{26}$, es decir una enseñanza mínima. Rubio no indica en que clase ha de empezar esta enseñanza, se limita a decir que los alumnos deben tener «cierta edad». Sin duda se refiere a los que dominan la caligrafía. Tampoco da Rubio método para la enseñanza, pues según él todo depende del maestro. El «buen maestro» explicará las reglas con claridad. Parece pensar que ser un buen maestro es un don, y que por tanto es difícil dar consejos en ese tema. Rubio tiene conciencia de los límites de su libro. No pretende formar al maestro ideal, sencillamente aspira a darles un plan coherente de estudios que permita uniformizar la enseñanza primaria en Madrid, en un primer momento, en el resto de España después. A partir de allí, cada maestro se las arregla como mejor pueda.

La actitud de Torío es de nuevo mucho más científica. Pretende darles a los maestros todos los conocimientos que necesitan para pasarlos a los alumnos. Vincula como Rubio el aprendizaje de la ortografía con el de la gramática, pues considera que la primera es parte de la segunda. Divide a los alumnos en tres clases: los principiantes, que ven los tratados de ortografía y gramática por primera vez, los de la segunda clase estudian estos libros por segunda vez y los de la tercera por tercera vez. El método adoptado es de nuevo el uso de la memoria y de la repetición excesiva.

En cuanto al contenido, se parece bastanta a lo que proponía Scío: papel y empleos de las letras, acentos, puntuación. Elabora a continuación una lista de palabras con

26. Rubio, op. cit., p. 32. 
una ortografía delicada. Para la gramática, considera las palabras según su categoría gramatical: nombre, pronombre, artículo y verbo. Estudia luego las conjugaciones, los participios, los adverbios, las preposiciones, etc. Por fin, dedica un capítulo a la sintaxis y otro a la prosodia.

Para verificar la buena asimilación de estos conocimientos por los alumnos, le propone al maestro una serie de preguntas y repuestas como las que proponía en aritmética, y que muestran que lo único que espera Torío es una recitación correcta ${ }^{27}$. Este tipo de preguntas no permite saber si las definiciones han sido realmente comprendidas. Tampoco se sabe si el alumno es capaz o no de aplicar las reglas. Estamos muy lejos del método a la vez teórico y práctico de Scío y del de Rubio, aparentemente basado en la explicación de reglas.

Además del contenido de la enseñanza y de la didáctica de cada disciplina, los tratados de enseñanza intentan definir cuál ha de ser el método para que los niños trabajen en las aulas, por el miedo o por la emulación.

\subsection{Disciplina}

Los educadores, de manera general, se interrogan sobre la necesidad de castigar a los alumnos ${ }^{28}$. Para ellos, es utópico lograr que los niños estudien sin una verdadera disciplina, es decir sin un sistema de castigos y recompensas. Pero la nueva concepción del niño que se define en el siglo XVIII tiene como consecuencia una inversión de la relación castigos/recompensas a favor de las segundas. Tres palabras aparecen en los tratados: suavidad, indulgencia y amor. Los maestros ya no quieren castigar a los que no logran leer o escribir una página. Prefieren recompensar a los que logran hacerlo. No se trata pues de culpabilizar sino de estimular a los niños. El maestro tiene que mostrarse paciente, aplicado y lleno de celo, como lo precisa Scío ${ }^{29}$. Para Rubio, el maestro debe ser sabio, humano y muy atento al niño, pues debe ser un ejemplo para el alumno. Torío adopta una posición equivalente: el maestro debe castigar con suavidad a sus alumnos, pues así éstos «conocerán que quien los corrige y castiga no es un tirano que los aborrece, sino un superior que los ama tiernamente ${ }^{30}$. Pone esto de realce la noción de ejemplaridad, verdadera innovación ya que hasta entonces prevalecían los latigazos, que de hecho tardarán bastante en desaparecer. Puede decirse sin embargo que se percibe una nueva actitud pedagógica entre un grupo de maestros ilustrados. A los castigos corporales, se prefiere una serie de reprensiones, como lo propone Rubio: «el poste, la postura incómoda, una o dos palmetas, la privación de

27. Se puede dar un ejemplo de esas preguntas, Torío, op. cit., p. 366:

«Maestro: ¿qué es la sintaxis?

Discípulo: la parte de la gramática que enseña a unir, trabar o enlazar entre sí las partes de la oración para traducir y componer el período».

28. Sobre este aspecto, véase el artículo de Aymes, Jean-René, "Vers de nouveaux rapports maítresélèves dans I'Espagne de la seconde moitié du XVIIlème siècle» in Matériaux pour une histoire de la scolarisation en Espagne et en Amérique latine (XVIII ${ }^{\circ}$-XIX ${ }^{\circ}$ siècles), Tours, Publications de I'Université de Tours, 1990, p. 122 a 128 en particular.

29. Scío, ibid, p. 2.

30. Torío de la Riva, op. cit., p. 164. 
un gusto, o falta de condescendencia, la inferioridad de puesto, la segregación y descenso de clase, la exclusiva en los alicientes, etc...son castigos suficientes para los castigos escolares ${ }^{31}$. Progresivamente, se condenan los castigos corporales. Así, en 1796, se suspende al maestro del barrio de San Andrés en Madrid, que, ebrio, había castigado física y violentamente a un niño, lo que había dado lugar a una denuncia de la familia ${ }^{32}$. Aunque seguramente la suspensión del maestro se debe a su embriaguez, no cabe duda de que se ha producido un cambio en las mentalidades: parece que el castigo corporal ya no es algo normal en la escuela.

Son las recompensas las que tienen que ser utilizadas para alentar a los niños a que trabajen, y en esto también se aprecia un cambio. Hasta entonces, se solía dar a los niños recompensas de escaso valor (corona de cartón por ejemplo) o bonos que compraban indulgencias para los próximos castigos. A Rubio le parece que esto sólo fomenta la vanidad (para las primeras) y el vicio, ya que el niño podía creerse autorizado a comportarse mal, al sentirse protegido por los bonos. Propone en su lugar una serie de buenas recompensas: sonrisas, alabanzas ante los otros alumnos, pequeños regalos (libro, imagen, fruta o golosina) ${ }^{33}$.

Para apreciar los progresos en los conocimientos de los alumnos, se preconiza una serie de exámenes privados semanales (Scío) o trimestriales (Semanario de nobles). También se reanuda con una práctica establecida por los jesuitas en sus colegios: los exámenes públicos anuales. Rubio organiza un examen de este tipo en 1787, para mostrar la eficacia de su método ${ }^{34}$. Los resultados fueron tan satisfactorios que Floridablanca otorgó gratificaciones a los maestros y a un alumno particularmente meritorio. Estos exámenes públicos parecen haber seducido al gobierno, ya que en 1791, cuando se crearon las escuelas reales, encontramos en El Diario de Madrid convocaciones de examen público para niños. En el Reglamento de las escuelas de primeras letras de 1797, se oficializan los exámenes públicos anuales para todos los niños de Madrid. Las recompensas eran entonces de dos tipos: ropa o pequeñas cantidades de dinero, lo que podía representar un estímulo tanto para los niños como para las familias, que quizás aceptaban así más fácilmente que su hijo acudiera a clase.

Como puede apreciarse, es todo el sistema educativo del siglo XIX el que los educadores de la segunda mitad del siglo XVIII establecen, con su disciplina basada en las recompensas y los castigos, los exámenes y los premios de excelencia.

\section{Conclusión}

En las diferentes disciplinas que hemos evocado aquí y que constituyen la base de la enseñanza elemental masculina, se puede notar un verdadero deseo por parte de ciertos maestros de reformar la enseñanza racionalizándola y poniéndola al alcance de todos. Esto es particularmente cierto en el caso de Scío, Anduaga y Rubio, que Ilevan escuelas para los niños de las clases populares o pobres. El contenido de la enseñanza

31. Rubio, op. cit., p. 25.

32. Archivo de Villa de Madrid, Corregimiento, 1-97-118.

33. Rubio, ibid, p. 20-21.

34. Gaceta del 2 de octubre de 1787, reproducida en nota por Rubio, ibid., p. 3-5. 
y los métodos de que se valen muestran una real adecuación con las necesidades de esos niños. No consideran para ellos la posibilidad de cursar estudios superiores, aunque tampoco se la prohíban, como lo indica la existencia de la iniciación al latín, puerta abierta a la clase de latinidad que existe en las escuelas pías. Al contrario de estos maestros, Torío parece algo más elitista, en la medida en que sus exigencias en cuanto a aritmética, gramática y ortografía son superiores a las de sus colegas. Esto se explica por el hecho de que su enseñanza fue elaborada en el Seminario de nobles, donde el público tenía forzosamente acceso a los estudios de latinidad.

La posición del Estado en cuanto a la elección de los programas para las escuelas de primeras letras varía según los reyes y sobre todo los ministros. Así, la desgracia de Floridablanca en 1792 marca el final de la supremacia de los métodos de Anduaga y Rubio. No cabe duda de que esto da paso a otros educadores como Torío de la Riva. El Estado desea uniformizar la enseñanza, pero le resulta difícil fijar la política educativa en esta segunda mitad del siglo XVIII.

Falta subrayar un silencio de los tratados: ninguno evoca la finalidad práctica de esta enseñanza. Los maestros consideran las primeras letras como un bloque, ya que en unos cuatro o cinco años el niño tiene que aprender todo lo que necesitará en su vida adulta. Por se insiste tanto en la perfecta moralidad que debe adquirir el niño. Saldrá de la escuela en una edad aún muy tierna y es preciso que el maestro cuide de que el niño siga el camino de la virtud y de la religión, normas imprescindibles de la vida en sociedad en la época. Estas escuelas deben ser además eficaces, pues todos los maestros saben que, al salir, el niño se dedicará al aprendizaje de un trabajo. La enseñanza de las primeras letras, para los humildes, no tiene por lo tanto otra finalidad que la puesta en condiciones del futuro trabajador. No se trata de ascensión social individual por la educación, concepto demasiado moderno para la Ilustración. Tan sólo se tratar de formar a un ser capaz de integrarse en la sociedad lo más eficazmente posible, como individuo y como trabajador, para alcanzar la armonía social, ideal de la política reformista ilustrada.

\section{Bibliografía}

AYMES, Jean-René, "Les Ilustrados espagnols de la seconde moitié du XVIIlème siècle et I'enseignement primaire. Etude comparative» p. 9-48 in Ecole et société en Espagne et en Amérique latine (XVIII - XXème siècles), Tours, CIREMIA, Publications de I'Université de Tours, 1983, 185 p. (Série «Etudes hispaniques»: V).

DEMERSON, Paulette, "Tres instrumentos pedagógicos del siglo XVIII: la Cartilla, el Arte de escribir y el Catón» p. 31-40 in: L'enseignement primaire en Espagne et en Amérique latine du XVIIlème siècle à nos jours. Politiques éducatives et pratiques scolaires, Tours, CIREMIA, Publications de I'Université de Tours, 1986, 632 p. (Série «Etudes hispaniques»: VI-VII).

La educación en la Ilustración española, Madrid, publicaciones del Ministerio de Educación y ciencia, 1988, 511 p., (Revista de Educación, número extraordinario).

JULIA, Dominique, "Aprendizaje de la lectura en la Francia del Antiguo Régimen», Revista de Educación, n² 288, enero-abril de 1989, p. 105-120. 
HERNÁNDEZ FRAILE, Paloma, Catálogo bibliográfico de obras de pedagogía de la Ilustración, Madrid, Centro de Publicaciones del Ministerio de Educación y ciencia, 1988, 192 p.

RUIZ BERRIO, Julio, «Reformas de la enseñanza primaria en la España del Despotismo ilustrado: la reforma desde las aulas» p. 3-17, in L'enseignement primaire en Espagne et en Amérique latine du XVIIlème siècle à nos jours. Politiques éducatives et pratiques scolaires, Tours, CIREMIA, Publications de I'Université de Tours, 1986, 632 p. (Série «Etudes hispaniques»: VI-VII). 